\title{
Deep Eutectic Solvents as an Alternate to Other Harmful Solvents
}

\author{
T. Raja Sekharan ${ }^{1,2}{ }^{\mathbb{D}}$, R. Margret Chandira ${ }^{1, *}$, Shunmugaperumal Tamilvanan ${ }^{3}{ }^{\mathbb{C}}$, S.C. Rajesh ${ }^{4}$, B.S. \\ Venkateswarlu ${ }^{1}$
}

1 Department of Pharmaceutics, Vinayaka Mission's College of Pharmacy, Vinayaka Mission's Research Foundation (Deemed to be University), Salem-636308, Tamil Nadu, India

2 Department of Pharmaceutics, Sankaralingam Bhuvaneswari College of Pharmacy, Anaikuttam-626130, Sivakasi, Tamil Nadu, India

3 Department of Pharmaceutics, National Institute of Pharmaceutical Education and Research (NIPER)-Guwahati, C/O NETES Institute of Technology \& Science, Mirza, Assam, India

4 Department of Pharmaceutical Analysis, Sankaralingam Bhuvaneswari College of Pharmacy, Anaikuttam-626130, Sivakasi, Tamil Nadu, India

* Correspondence: mchandira172 @gmail.com;

Scopus Author ID 36114451300

Received: 23.02.2021; Revised: 6.04.2021; Accepted: 8.04.2021; Published: 26.04.2021

\begin{abstract}
Solvents generally in liquid form, are used to dissolve, dilute, suspend any substances or extract other materials. More than one-third of the drugs listed in the various Pharmacopeias fall into the poorly water-soluble or water-insoluble categories. For more than 200 years, traditional solvents could be used as a solvent for substances that were insoluble in water. But the usage of these types of solvents should be decreased because these types of solvents are volatile, flammable, and often toxic. Also, the industrialist's usages in different types of processes prove the risk for workers. In recent years, several solvents have been proposed to be the greener replacement for traditional solvents. Replacing hazardous chemicals with more environmentally friendly alternatives is a matter of current interest, in line with the philosophy of Green Chemistry. The use of nontraditional or nonconventional solvents such as supercritical fluids (SCFs) such as Carbon dioxide $\left(\mathrm{CO}_{2}\right)$ and water, fluorous solvents, solventless reaction Ionic liquids (ILs) and their derivatives [polymeric ILs and magnetic ILs], and deep eutectic solvents (DESs) are alternatives for environmentally unfriendly traditional solvents. Among them, DES is a neoteric class of green solvents defined as a mixture of two or more compounds that are typically solid at room temperature, but when combined at a particular molar ratio, changes into a liquid at room temperature. It is assumed that eutectic mixtures show low volatility, have a broad liquid range, and are water-compatible, non-flammable, non-toxic, biocompatible, and eco-friendly. Eutectic solvents have been useful in several pharmaceutical fields, such as the increase of drug solubility, permeation, and absorption.
\end{abstract}

Keywords: green solvent; deep eutectic solvents; natural deep eutectic solvents; therapeutic deep eutectic solvents; polymeric deep eutectic solvents; hydrophilic deep eutectic solvents; hydrophobic deep eutectic solvents.

\section{Abbreviation:}

API: Active Pharmaceutical Ingredients; DES: Deep Eutectic Solvents; ILs: Ionic Liquids; HBA: Hydrogen Bond Acceptor; HBD: Hydrogen Bond Donor; $\mathrm{CHCl}$ : Choline chloride; NADES: Natural Deep Eutectic Solvent; THEDES: Therapeutic Deep Eutectic Solvent; PODES; Polymeric Deep Eutectic Solvent.

(C) 2021 by the authors. This article is an open-access article distributed under the terms and conditions of the Creative Commons Attribution (CC BY) license (https://creativecommons.org/licenses/by/4.0/). 


\section{Introduction}

The word "Solvents" gets from the Latin term, which generally means "loosen". Solvents, which are normally large in fluid-structure, are utilized to break up, weaken, suspend any substances, or take out different materials, as a rule with no concoction change either in the solvents or additional materials [1]. Solvents are nearly being used in all the sort of ventures. Solvents are essential to most regions of science, including synthesis, testing, pharmaceutical, nourishment and flavor science, and the materials and painting industry [2]. Solvents are fundamental in all the pharmaceuticals territory, including dissolving active pharmaceutical ingredients (API) and different excipients, for scientific reason, for covering, and so forth. Among all the solvents, water is the most widely recognized dissolvable on the planet [3].

The choice of water as a dissolvable is because of various reasons, little of them are: (a) It is low-priced and promptly accessible in an unadulterated form; (b) It is non-lethal; (c) It isn't extremely thick and can be effectively poured starting with one vessel then onto the next. Activities, for example, crystallization and filtration, can be promptly completed; (d) It is a decent dissolvable for dissolving a wide assortment of solutes [4].

Still, numerous substances are not dissolvable or can counter with water, and a few responses are impractical in water because of dissolvable impacts [3]. More than $33 \%$ of the medications recorded in different Pharmacopeias fall into the inadequately water-solvent or water-insoluble classifications. The rise of huge quantities of ineffectively solvent medication applicants has prompted the need for creating systems to conquer the impediments in tranquilize item advancement related to poor dissolvability [5]. The drug/excipients/other substances which are not soluble in water can be dissolved in traditional/conventional organic solvents [6]. Traditional organic solvents are often regulated as volatile organic compounds (VOCs) [7].

VOCs and petrochemical solvents are utilized to break down certain API. However, the utilization of these kinds of solvents ought to be diminished, the fact that these sorts of solvents can evaporate at room temperature, unstable, unpredictable, combustible, and frequently lethal. Additionally, the industrialist's utilization in various sorts of procedures demonstrates laborers' hazard. Thorough security necessities method ought to be followed during usage [8]. However, a major number of solvents utilizing are hazardous to human healthiness and nature. Developing new green solvents is one of the key subjects in Green Chemistry [3].

Green chemistry is defined as the design of chemical products. The procedure involved should lessen and/or reduce/remove the use of dangerous substances [9]. Green solvents are always being developed to alternate hazardous solvents with better healthiness, protection, and ecological properties [10].

Green solvents like supercritical fluids, supercritical water, ionic liquids, DES, switchable solvents, supramolecular solvents, surfactants, etc. [11] can replace conventional organic solvents. Our study in this review covers a detailed summary of DESs as a green solvent.

\section{Eutectic Mixtures (EM)}

Eutectic mixtures from the Greek word meaning eutēktos meaning "easily melted" [5]. In the formulation, eutectic mixtures have been used to improve drug solubility, permeation, and absorption. For emulsion preparation, EM has been used as an oil phase [12]. 


\subsection{Chemistry of DESs.}

The melting point of two components, solid A and solid B, strongly depends upon their reciprocal interaction: when considering a binary mixture of solid $\mathrm{A}+$ solid $\mathrm{B}$, the difference in the freezing point at the eutectic composition compared to that of a theoretical ideal mixture which is directly proportional to the interaction between the two single components solid A and solid B. The stronger the interaction, the larger will be the depression of the mixture melting point [13]. This effect is schematically shown in the phase diagram presented in figure 1.

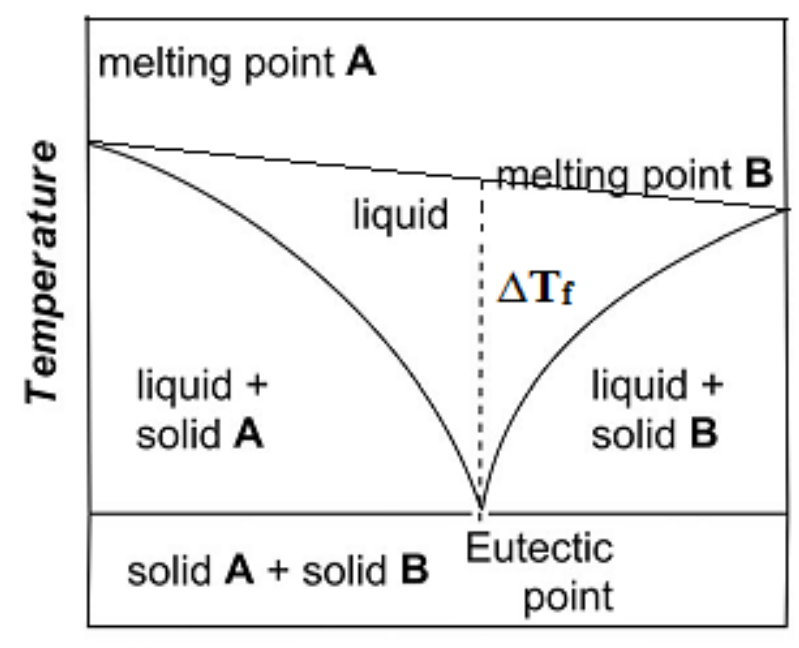

\section{pure A Mole fraction of B pure B}

Figure 1. Eutectic formation phase diagram for two solid compounds, A and B, form a simple eutectic with no new compound formation.

\subsubsection{Deep eutectic solvent (DES).}

In 1884, the British physicist Frederick Guthrie coined the term eutectic, derived from the Greek $\varepsilon v \tau \eta \kappa \tau o \zeta$, which means "easy (or lowest than an individual) liquefaction" [14]. A DES is a new class of solvents [15]. It is defined as a mixture of two or more compounds that are typically solid at room temperature, but when combined at a particular molar ratio, changes into liquid at room temperature [16]. DESs were easily synthesized by mixing two naturally occurring components, namely hydrogen bond acceptor (HBA), such as quaternary ammonium halide salts, phosphonium halide salts, and metal chloride, and hydrogen bond donors (HBD) such as carboxylic acids, alcohols, amides, carbohydrates and metal chloride which associated to each other through hydrogen bond interaction [17].

Complexation between HBD and HAD results in charge delocalization which makes the DESs with large, non-symmetric ions, and it has low lattice energy and results in low melting points compared to an individual substance [18]. The extensive hydrogen-bonded network is responsible for the mixture's reduced melting point compared to those of the individual components [19]. DESs are composite solvents with a melting point considerably lower $\left(>50{ }^{\circ} \mathrm{C}\right)$ than what would be expected for the pure component melting points of their constituents [20].

Liquid and liquid interactions in the liquid mixture are a lot more complicated than a pure liquid due to the possibility of better solvation and liquid-liquid interactions. Consequently, DESs can be used as solvents in a combination of dual or triple solvents to increase the effectiveness of processes and encourage solvents' physical and chemical properties [21]. For the pharmaceutical field, the eutectic system has been applied for many 
purposes, such as increasing drug solubility, permeation, and absorption or applying as oil phase in emulsion system [22]. ES's advantages are that it's less toxic, inexpensive, ecofriendly, and non-flammable [23].

\subsubsection{Classification of DESs.}

Depending upon the nature of the complexing agent Abbott and co-workers classified DESs into four types, as shown in table 1.

Table 1. Classification of DESs.

\begin{tabular}{l|l} 
Type & HBD and HBA \\
\hline I & Organic salt + metal salt \\
\hline II & Organic salt + metal salt hydrate \\
\hline III & Organic salt + hydrogen-bond donor \\
\hline IV & Metal salt + hydrogen-bond donor
\end{tabular}

\subsubsection{Pathway of DES.}

From 1994 to now, the pathway of eutectic solvents (ES) [8] is shown in table 2.

Table 2. Pathway of different DESs.

\begin{tabular}{l|l} 
Year & Pathway of ES \\
\hline 1994 & The substrate for enzymatic reactions/synthesis \\
\hline 1995 & Separation and purification of molecular mixtures \\
\hline 1998 & Usage of enzymatic reactions/synthesis in larger applications and novel industrial development \\
\hline 2003 & Replacement to ILs \\
\hline 2006 & Ionothermal analysis of zeolites \\
\hline 2007 & In the field of electrochemistry \\
\hline 2010 & Biocatalytic process \\
\hline 2012 & Enzyme catalysis and whole-cell biocatalysis process \\
\hline 2013 & NADES \\
\hline 2015 & Hydrophobic DESs
\end{tabular}

\subsubsection{Preparation of DES.}

Usually, DESs can be prepared by any one of the following techniques that appeared in table 3. Commonly, DESs are prepared by mixing the components in a mortar and pestle by trituration method. This method is useful when the composition of DES ingredient is in equal amounts. If the blended mixture is hazy i.e., unclear then the obtained hazy liquid can be placed into a magnetic stirrer and allowed to rotate for a few minutes to hr without applying any heat until a clear liquid was obtained.

Table 3. Preparation of DESs by different methods

\begin{tabular}{l|l|l} 
Technique/Method & Procedure & $\begin{array}{l}\text { Entil formation of } \\
\text { clear liquid }\end{array}$ \\
\hline $\begin{array}{l}\text { Mortar and pestle } \\
\text { Mixing in magnetic } \\
\text { stirrer without heat }\end{array}$ & Mix two components in mortar and pestle & $\begin{array}{l}\text { Until formation of } \\
\text { clear liquid }\end{array}$ \\
\hline $\begin{array}{l}\text { Mixing in magnetic } \\
\text { stirrer with slight/more } \\
\text { heat }\end{array}$ & Mix two components in a magnetic stirrer with slight/more heat & $\begin{array}{l}\text { Until formation of } \\
\text { clear liquid }\end{array}$ \\
\hline $\begin{array}{l}\text { Freezing } \\
\text { Vacuum evaporating }\end{array}$ & $\begin{array}{l}\text { Mighly viscous sugar-based DESs are difficult to stir. This problem } \\
\text { can be overcome by adding extra water into the mixture. Then } \\
\text { evaporate the water at } 323 \mathrm{~K} \text { using a rotary flash evaporator. Keep the } \\
\text { obtained DESs in a desiccator containing silica gel until uniform } \\
\text { weight is attained }\end{array}$ & $\begin{array}{l}\text { Until formation of } \\
\text { clear liquid }\end{array}$ \\
\hline
\end{tabular}


There is no need to apply heat to obtain a clear DES for components in equal proportion. If the ratio of any one component is kept constant and the other component ratio is increased, even mixing for a long time without heating results in no formation of clear DES. At that condition, if the temperature is increased (slight to more) depending upon the ratio, it results in a formation of clear DESs. DESs can also be made using the freezing process, which involves mixing the ingredients and freezing them to produce a transparent liquid. The vacuumevaporating method can also be used to prepare DES. It is difficult to stir highly viscous sugarbased DESs; however, this problem can be solved by adding water to the mixture. The water in the DESs can then be vaporized using a rotary flash evaporator at $323 \mathrm{~K} / 49.85^{\circ} \mathrm{C}$ using a vacuum-evaporating process [24].

EM or ES can be formulated between (a) a pair of naturally occurring excipients said to be NADES [25], (b) between APIs and excipients or between at least two APIs called therapeutic DES [26] (c) incorporating any polymers to the ES known as polymeric DES [23].

\subsubsection{Natural deep eutectic solvents (NADES).}

NADESs is an attractive sort of DESs. When DES is prepared from neutral, acidic, or basic ingredients that are obtained naturally, are said to be NADES. It has been used to alternate organic solvents in various fields [27]. NADES comprising natural compounds, such as organic acids, amino acids, and sugars, have been recently developed for possible application in the natural product field [28]. The NADESs are obtained by mixing HBA (usually choline chloride $(\mathrm{CHCl})$, lactic acid, betaine hydrochloride, tetrabutylammonium chloride, trioctyl ammonium chloride) and HBD (generally natural plant-based organic species, such as amino acids, carboxylic acids, sugars, and sugar alcohols) in a specific molar ratio at different temperatures [29]. Even though only at the beginning stage, studies on NADESs have started to bud with exponential growth, showing attractiveness and shows potential for use in various areas [30]. NADESs non-volatile below atmospheric conditions, are chemically and thermally stable, nonflammable, and have great dissolvable properties for several organic compounds [28]. The high viscosity of most DES at room temperature limits their application as extraction solvents. To overcome these drawbacks, NADES were introduced. NADES can be prepared in a large number of combinations [8]. Few compounds isolated with NADESs are shown in table 4.

Table 4. Compounds isolated with NADESs

\begin{tabular}{|c|c|c|c|c|c|c|}
\hline \multirow[b]{2}{*}{ Compound } & \multirow[b]{2}{*}{ From } & \multicolumn{3}{|c|}{ NADES } & \multirow[b]{2}{*}{ Year } & \multirow[b]{2}{*}{ Ref } \\
\hline & & HBD & HBA & $\begin{array}{l}\text { Highest extraction } \\
\text { composition }\end{array}$ & & \\
\hline Anthocyanins & $\begin{array}{l}\text { Molina } \\
\text { chequen })\end{array} \quad$ (Luma & \multicolumn{2}{|c|}{$\begin{array}{l}\mathrm{CHCl} \text {, citric acid, glucose, glycerol, } \\
\text { lactic acid, and tartaric acid }\end{array}$} & $\begin{array}{l}\text { Lactic acid:Glucose } \\
(8: 1)\end{array}$ & 2021 & [28] \\
\hline $\begin{array}{l}\text { Phenolic } \\
\text { Compounds } \\
\text { (phenol and } \\
\text { flavonoids) }\end{array}$ & $\begin{array}{l}\text { Chokeberry (Aronia } \\
\text { melanocarpa) }\end{array}$ & $\mathrm{CHCl}$ & $\begin{array}{l}\mathrm{D}-(-) \quad \text { fructose, } \mathrm{D}(+) \\
\text { glucose, lactic acid, and } \\
\text { urea }\end{array}$ & $\mathrm{CHCl}$ :Fructose & 2020 & [30] \\
\hline Flavonoids & Buckwheat sprouts & $\mathrm{CHCl}$ & $\begin{array}{l}\text { 1,2-propanediol, 1,4- } \\
\text { butanediol, acetamide, } \\
\text { ethylene glycol, glycerol, } \\
\text { melonic acid, oxalic acid, } \\
\text { triethylene glycol, and } \\
\text { urea, }\end{array}$ & CHCl:Acetamide & 2019 & [31] \\
\hline Polyphenol & Orange peel & $\begin{array}{l}\text { Glycerol } \\
\text { and } \\
\text { ethylene } \\
\text { glycol }\end{array}$ & $\mathrm{CHCl}$ & $\begin{array}{l}\text { CHCl:Ethylene } \\
\text { Glycol (1:4) }\end{array}$ & 2018 & [32] \\
\hline Vanillin & Vanilla pods & $\begin{array}{l}\text { Combinat } \\
\text { betaine, } \mathrm{b}\end{array}$ & $\begin{array}{l}\mathrm{n} \text { of 1,2-propanediol, } \\
\text { aine, } \mathrm{CHCl} \text {, citric acid, D- }\end{array}$ & $\begin{array}{l}\text { Lactic acid: } 1,2- \\
\text { propanediol }(1: 1)\end{array}$ & 2017 & [33] \\
\hline
\end{tabular}




\begin{tabular}{|c|c|c|c|c|c|c|}
\hline \multirow{3}{*}{ Compound } & \multirow{3}{*}{ From } & \multicolumn{3}{|c|}{ NADES } & \multirow{3}{*}{ Year } & \multirow{3}{*}{ Ref } \\
\hline & & HBD & HBA & $\begin{array}{l}\text { Highest extraction } \\
\text { composition }\end{array}$ & & \\
\hline & & \multicolumn{2}{|c|}{$\begin{array}{l}\text { fructose, D-glucose monohydrate, } \\
\text { glycerol, lactic acid, lactic acid, L- } \\
\text { serine, malic acid, sucrose, water, and } \\
\beta \text {-alanine, }\end{array}$} & & & \\
\hline Polyphenols & $\begin{array}{l}\text { Thyme, Oregano, } \\
\text { Greek sage and Sage }\end{array}$ & $\begin{array}{l}\text { Lactic } \\
\text { acid }\end{array}$ & $\begin{array}{l}\text { Ammonium acetate, } \\
\mathrm{CHCl} \text {, glycine, L-alanine, } \\
\text { nicotinamide, sodium } \\
\text { acetate, and } \beta \text { - } \\
\text { Cyclodextrin }\end{array}$ & $\begin{array}{l}\text { Lactic } \\
\text { acid:Nicotinamide } \\
\text { with } \beta \text {-Cyclodextrin }\end{array}$ & 2017 & [34] \\
\hline $\begin{array}{l}\text { Polyphenolic } \\
\text { compounds }\end{array}$ & $\begin{array}{l}\text { Dittany, Fennel, } \\
\text { Marjoram, Mint and } \\
\text { Sage }\end{array}$ & $\begin{array}{l}\text { Lactic } \\
\text { acid }\end{array}$ & $\begin{array}{l}\text { Ammonium } \\
\mathrm{CHCl} \text {, glycine, sotate, } \\
\text { acetate, and water }\end{array}$ & $\begin{array}{l}\text { Lactic } \\
\text { acid:Glycine:Water } \\
(3: 1: 3)\end{array}$ & 2016 & [35] \\
\hline $\begin{array}{l}\text { Polyphenolic } \\
\text { compounds }\end{array}$ & Virgin olive oil & $\mathrm{CHCl}$ & $\begin{array}{l}\text { 1,2-propanediol, 1,4- } \\
\text { butanediol, glycerol, lactic } \\
\text { acid, malonic acid, } \\
\text { sucrose, urea, and xylitol }\end{array}$ & $\begin{array}{l}\mathrm{CHCl}: \mathrm{Xylitol}(2: 1) \\
\text { and } \mathrm{CHCl}: 1,2- \\
\text { propanediol }(1: 1)\end{array}$ & 2016 & [36] \\
\hline Rutin & Sophora japonica & $\mathrm{CHCl}$ & $\begin{array}{l}\text { 1,4-butanediol, acetamide, } \\
\text { citric acid, D-sorbitol, } \\
\text { ethylene glycol, fructose, } \\
\text { glucose, glycerol, } \\
\text { levulinic acid, malic acid, } \\
\text { malonic acid, maltose, } \\
\text { oxalic acid, p- } \\
\text { toluenesulfonic acid, } \\
\text { sucrose, tartaric acid, } \\
\text { triethylene glycol, urea, } \\
\text { xylitol, and xylose }\end{array}$ & $\begin{array}{l}\text { CHCl:Triethylene } \\
\text { glycol (1:4) } \\
\text { containing } 20 \% \\
\text { water }\end{array}$ & 2015 & [37] \\
\hline $\begin{array}{l}\text { Rotenone } \\
\text { (Isoflavanoid) }\end{array}$ & $\begin{array}{l}\text { Derris species roots } \\
\text { (Derris } \\
\text { elliptica and Derris } \\
\text { malaccensis) }\end{array}$ & $\mathrm{CHCl}$ & 1,4-butanediol & $\begin{array}{l}\mathrm{CHCl}: 1,4- \\
\text { butanediol (1:5) with } \\
\text { acetonitrile }\end{array}$ & 2015 & [22] \\
\hline
\end{tabular}

2.1.3. Therapeutic deep eutectic system (THEDES).

THEDES is a type of DES having API as one of its components [20]. THEDES is defined as a mixture of two components, one of which is an API, at a specific molar composition, become liquid at room temperature [38]. In the pharmaceutical field, the eutectic system has been used in many proposes. The liquid solution obtained from a eutectic mixture has been applied for some drugs to increase solubility, permeation, and absorption or used as oil phase in the emulsion system [39]. The eutectic mixture can be prepared by synthetic polymers and natural polymers like urea-based (proline-urea), sugar and organic acid-based (citric acid-glucose), organic acid and amino acids-based (malic acid, glutamic acid, lactic acid, etc.), CHCl-based, etc. [40]. THEDES formed with few eutectic forming components, and the drug is shown in table 5.

Table 5. THEDES prepared with eutectic forming component and drug.

\begin{tabular}{l|l|l|c|c}
$\begin{array}{l}\text { Eutectic forming } \\
\text { ingredients/drug }\end{array}$ & Drug & Obtained benefits & Year & References \\
\hline Menthol & $\begin{array}{l}\text { Stearic acid, myristic } \\
\text { acid, and lauric acid }\end{array}$ & Wound curing & 2019 & {$[41]$} \\
\hline Ascorbic acid and CHCl & Dexamethasone & $\begin{array}{l}\text { Increase in solubility, diffusion } \\
\text { and permeability }\end{array}$ & 2018 & {$[42]$} \\
\hline $\mathrm{CHCl}$ and menthol & $\begin{array}{l}\text { Acetylsalicylic acid, } \\
\text { benzoic acid and } \\
\text { phenylacetic acid }\end{array}$ & $\begin{array}{l}\text { Dissolution enhancement and } \\
\text { antibacterial activity }\end{array}$ & 2016 & {$[20]$} \\
\hline Lidocaine & Tetracaine & Local anesthetic action & 2008 & {$[43]$} \\
\hline Menthol & Ibuprofen & $\begin{array}{l}\text { To enhance the rectal } \\
\text { bioavailability of ibuprofen. }\end{array}$ & 2004 & {$[44]$} \\
\hline Poly(ethylene glycol) & Fenofibrate & Dissolution improvement & 2003 & {$[45]$}
\end{tabular}




\begin{tabular}{l|l|l|l|l}
\hline $\begin{array}{l}\text { Eutectic forming } \\
\text { ingredients/drug }\end{array}$ & Drug & Obtained benefits & Year & References \\
\hline Menthol & Ubiquinone & $\begin{array}{l}\text { To overcome the drawbacks like } \\
\text { low solubility and irreversible } \\
\text { precipitation of Ubiquinone }\end{array}$ & 2002 & {$[46]$} \\
\hline $\begin{array}{l}\text { Terpene binary mixtures (p- } \\
\text { cymene, D-limonene, thymol, 1,8- } \\
\text { cineole, menthol, menthone) }\end{array}$ & $\begin{array}{l}\text { Ibuprofen } \\
\text { permeation in transdermal }\end{array}$ & 1998 & {$[47]$}
\end{tabular}

\subsubsection{Polymeric deep eutectic solvent (PODES).}

Any polymer dissolved into the prepared eutectic mixture then it is said to be PODES. Various polymers can be used to dissolve in the vehicle to prepare the polymeric eutectic system. Different physical properties like viscosity and rheology of the selected polymeric eutectic system will be evaluated. The obtained lowest viscosity liquid eutectic will be/can be used as a vehicle in the study. The drug release (immediate or sustained) from the formulations developed with polymeric liquid eutectic depends on the polymer's nature [48]. The advantage of this type of DES is cheaper to produce due to the lower cost of the raw materials, less toxic, and often biodegradable. The disadvantage of the DES is the high viscosity, and the solid-state of most DES at room temperature restricts their application as extraction solvents [7]. PODESs formed with few eutectic forming components, drug, and polymer are shown in table 6.

Table 6. PODES prepared with the eutectic forming component, drug, and polymers.

\begin{tabular}{l|l|l|c|c}
$\begin{array}{c}\text { Eutectic forming } \\
\text { compound }\end{array}$ & \multicolumn{1}{|c|}{ Polymer used } & \multicolumn{1}{|c|}{ Drug } & Year & References \\
\hline $\begin{array}{l}\text { Menthol:Camphor } \\
(1: 1)\end{array}$ & $\begin{array}{l}\text { Eudragit EPO, Eudragit } \\
\text { L100, Eudragit RLPO, } \\
\text { Eudragit RSPO, and } \\
\text { Eudragit S100 }\end{array}$ & $\begin{array}{l}\text { Aspirin, Azithromycin, Chloramphenicol, } \\
\text { Clotrimazole, Diclofenac sodium, Ibuprofen, } \\
\text { Indomethacin, Nevirapine, Paracetamol, and } \\
\text { Piroxicam, }\end{array}$ & 2012 & {$[48]$} \\
\hline $\begin{array}{l}\text { Menthol:Camphor } \\
(1: 1 \text { and 1:2) }\end{array}$ & Eudragit RL-100 & Ibuprofen & 2019 & {$[49]$}
\end{tabular}

\section{Classification of DES Based on Water Solubility}

Depends upon the water solubility DESs can be classified into hydrophilic DESs and hydrophobic DESs [50].

\subsection{Hydrophilic DES.}

Initially, research in DES paid much attention to hydrophilic DESs [51]. Due to their hydrogen bonding ability, DESs are generally hydrophilic and dissolve easily in an aqueous environment [52]. Since 2001 more than 1800 articles were published related to DES; most of them are related to hydrophilic DES [53]. Hydrophilic DESs are applied in many fields, including solvents or catalysts for chemical reactions, electrochemistry, pharmaceuticals, and separation process. Most DESs proposed in the reported articles were the hydrophilic DESs, which were not stable in water [54]. The main drawback of hydrophilic DES is only polar compounds can able to separate [53]. Hydrophilic DES unstable in water has been also reported [55]. In general, the density of hydrophilic DESs is higher when compared to water at room temperature, but increase in temperature results in a decrease in viscosity [56].

\subsection{Hydrophobic DES.}

For the past five years, hydrophobic DESs have emerged as an alternative extractive media capable of extracting non-polar organic and inorganic molecules from aqueous 
environments. The water-immiscible solvent was applied to extract water-insoluble volatile organic compounds, which reported a high extraction yield and efficiency [53].

The concept of hydrophobic DES (HDES) was introduced by Osch and co-workers [52] in 2015 when they combined diverse quaternary ammonium salts (QAS) with decanoic acid (DecA). Osch and his co-workers worked on the first hydrophobic DESs consisting of fatty acid and a quaternary ammonium salt. DecA is chosen as HBD for its high hydrophobic behavior in combination with 6 quaternary ammonium salts were chosen as HBA, namely

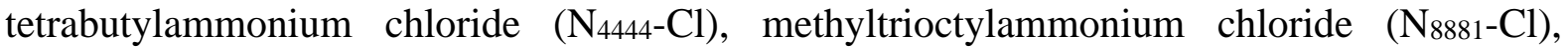
tetraheptylammonium chloride $\left(\mathrm{N}_{7777-\mathrm{Cl}}\right)$, tetraoctylammonium chloride $\left(\mathrm{N}_{8888} \mathrm{Cl}\right)$, methyltrioctylammonium bromide $\left(\mathrm{N}_{8881}-\mathrm{Br}\right)$ and tetraoctylammonium bromide $\left(\mathrm{N}_{8888}-\mathrm{Br}\right)$. With the help of these hydrophobic DESs they successfully evaluated the recovery of volatile fatty acids from dilute aqueous solutions.

Florindo et al. [57] and his research team focused on developing hydrophobic DESs, as inexpensive extractants for removing four neonicotinoids (imidacloprid, acetamiprid, nitenpyram, and thiamethoxam) from dilute wastewater by liquid-liquid extraction method. They used two families of DESs, one based on natural neutral ingredients (DL-menthol and natural organic acids) and the other based on quaternary ammonium salts $\left(\mathrm{N}_{4444} \mathrm{Cl}\right)$ and organic acids (acetic acid, levulinic acid, pyruvic acid, butyric acid, hexanoic acid, octanoic acid, decanoic acid, and dodecanoic acid) were used in their studies. They concluded that DLmenthol:octanoic acid is normally the most appropriate DES for removing pesticides from wastewater. The solvation properties of hydrophobic DES are favorable for both non-polar and polar compounds. It has also been shown to be effective in the extraction of organic and inorganic compounds [55].

Bioactive components like polyprenyl acetates, artemisinin, and neonicotinoids can be extracted with Hydrophobic DESs [58]. Yousefi et al. and his team [59] evaluated Carboxylic acid-Tetra- $n$-butyl ammonium bromide (TBAB) as hydrophobic DESs in microextraction methods based on solidification of floating drop (SFD). Hydrophobic DESs are suitable alternatives to common organic solvents and hydrophilic DESs in extraction processes. Polycyclic aromatic hydrocarbons (PAHs) are among the major environmental pollutants found in all environmental matrices such as water, soil, and atmosphere. They have attracted much attention due to their toxic, mutagenic, and carcinogenic properties. PAHs are a nonpolar or lipid-soluble nature, and they have low water solubility. In this work, TBAB acts as a hydrogen bond acceptor, and oleic acid, decanoic acid, octanoic acid, propionic acid, acrylic acid, acetic acid, and butyric acid in a 1:2 mol ratio act as hydrogen bond donors. Among all, the TBAB/2decanoic acid DES possessed the desirable properties as an extraction solvent in SFD, such as good hydrophobicity and proper freezing or melting point near room temperature $\left(15-20^{\circ} \mathrm{C}\right)$. They proved that carboxylic acid-based DESs could be suitable extractants for SFD-based liquid-phase microextraction methods. Dispersive liquid-liquid microextraction solidification of DES can be a powerful, fast, facile, environmentally compatible, and cheap method for the trace analysis of PAHs in water samples.

Dandan Ge et al. [60] used DL-menthol and decanoic acid at different ratios as a hydrophobic DES to extract parabens in water. They have collected water samples from different sources like tap, river, lake, and wastewater in Kunming, China. From the collected water sample, they analyzed different parabens contents like methylparaben, ethylparaben, propylparaben, and butylparaben by the proposed method. They concluded that they 
successfully determined four parabens in environmental water samples with acceptable recoveries by their proposed method.

Qu et al. [54] prepared five hydrophilic and three hydrophobic DES for the microextraction of sulfonamides in water samples. Five hydrophilic DESs were prepared with Choline chloride: Phenol (1:1), Choline chloride:Catechol (1:1 and 1:2), Choline chloride:Resorcinol (1:1 and 1:2). Three hydrophobic DESs were prepared with Choline Chloride: $o$-cresol, Choline Chloride: $m$-cresol, and Choline Chloride:p-cresol (1:2). Compared with the performance of five hydrophilic DESs in the water phase, the three hydrophobic DESs were more suitable for application in dispersive liquid-liquid microextraction to determine sulfonamides in the water sample. Their results revealed that three hydrophobic DESs showed commendable performance for extraction of sulfonamides in water samples.

Osch et al. [52] identified and characterized terpenes-based DES for extracting riboflavin from water. They identified 17 new hydrophobic DESs by testing 507 combinations of solid components. The maximum extraction of riboflavin $(81.1 \%)$ from water was attained with the Decanoic acid:Lidocaine (2:1).

Verma and Banerjee [55] worked in the extraction of lower alcohols (ethanol/propanol/butanol) from the aqueous phase with the help of a new, natural, hydrophobic DES based on DL-menthol (hydrogen bond acceptor (HBA) and palmitic acid (hydrogen bond donor (HBD) with different ratios. The recovered 1-butanol using DES was found to be lower than the conventional solvent, i.e., mesitylene.

Raja Sekharan et al. [49] and his team formulated Ibuprofen-loaded emulsion from the hydrophobic eutectic solvent prepared from Camphor and Menthol. Their work concluded that Ibuprofen emulsion was successfully formulated with Eudragit RL 100 in an eutectic mixture.

\section{Applications of DESs}

\subsection{DES in transdermal delivery.}

Stott et al. [47] have done a study on enhanced permeation of ibuprofen drug through transdermal delivery with the help of terpene eutectic system. A different range of ibuprofen:terpene binary mixtures were melted together, cooled, and recrystallized. The melting points of these systems were found to be $32^{\circ} \mathrm{C}$ for Ibuprofen:thymol $(40: 60 \% \mathrm{w} / \mathrm{w})$, $-13^{\circ} \mathrm{C}$ for Ibuprofen: 1,8 -cineole $(40: 60 \% \mathrm{w} / \mathrm{w})$ and $76^{\circ} \mathrm{C}$ for Ibuprofen alone. DSC and FT-IR analysis were used to determine the nature of the interaction. FT-IR studies indicated that only the terpenes which formed hydrogen bonds with ibuprofen produced eutectic systems. Their study concluded that ibuprofen forms eutectic systems with certain terpene penetration enhancers. The terpene is able to interact with ibuprofen and disrupt the hydrogen-bonded dimmers, the resultant melting point depression of the formulation correlated with a significant increase in transdermal flux.

\subsection{DES in a cream formulation.}

Zun et al. [61] formulated fluconazole cream with the help of salicylic acid-menthol and benzocaine-menthol as a eutectic mixture and evaluated for their physical properties. The formulated creams were subjected to physical tests such as spreadability, slip, and tenacity tests. Further, it was evaluated for their rheological properties. The fluconazole creams with eutectic mixtures had better physical properties when compared to the formulations formulated without an eutectic mixture. 
Ohzeki et al. [43] prepared a local anesthetic cream from a Lidocaine-Tetracaine eutectic mixture for the clinical treatment of postherpetic neuralgia. They prepared LidocaineTetracaine (LT cream) and Lidocaine-Prilocaine (LP cream) using the same base. The release rate of lidocaine from the formulated creams was examined using a cellulose ester membrane. The release rate of lidocaine from LT cream was similar to that of LP cream. The release rate of tetracaine was slightly slower than that of lidocaine in LT cream, reflecting the larger molecular size of tetracaine. With the help of Yucatan micropig skin, they examined the penetration rate. The penetration rate of lidocaine was similar between LT and LP creams. Infiltration anesthesia action examined in guinea pigs indicated that the difference between the two creams was statistically insignificant. Their study suggests the equivalence of the LT and LP creams as a local anesthetic for clinical use either in the easy formulation or in the low-cost formulation.

\subsection{DES in emulsion formulation.}

To eliminate the oil or oil combination and antioxidant molecule from the emulsions, a very attractive but less expensive alternative/replacement is the utilization of eutectic liquid made from eutectic forming excipients in the oil phase to prepare an oil-in-water emulsion. Since the developed emulsions contain water and emulsifier molecules, they do not have the oil or oil combination. It can conveniently be termed as oil-less emulsions. Tamilvanan et al. [62], with his co-researchers, formulated oil-less emulsion containing coriander seed powder in eutectic solvent prepared with camphor and menthol and tween 80 as a surfactant. They concluded that the potential of coriander-based oil-less emulsion in topical therapeutic use is very certain.

Biswal et al. [63] formulated and evaluated microemulsion-based topical hydrogels containing lornoxicam. Eutectic mixture of camphor and menthol was used as oily phase (maximum 10\%), solvent for lornoxicam, and also it acts as a powerful penetration enhancer. Tween 80, ethanol and Carbopol 934p, HPMC K-15M, and Xanthan gum were selected as a surfactant, co-surfactant, and hydrogel thickening agent, respectively. They obtained the concentration range of oil phase, surfactant, and co-surfactant for formulating microemulsion with ternary phase diagrams. The formulated hydrogel thickened microemulsions were characterized for $\mathrm{pH}$, viscosity, spreadability, in vitro drug transport study with excised rat skins, and in-vivo anti-inflammatory activity. Their results showed that the content of microemulsion-based hydrogel components had a significant effect on their physical, rheological, and in vitro drug release characteristics.

Shen et al. [64] enhanced intestinal absorption of daidzein by making it in a microemulsion formulation with the help of Borneol/Menthol eutectic mixture (25:75). They formulated their microemulsion, which consists of ethyl oleate (oil), Cremophor RH40 (surfactant), PEG400 (co-surfactant), and water. A pharmacokinetic study in rats was conducted by orally administering borneol:menthol eutectic solvents or daidzein suspension at a measured quantity of $10 \mathrm{mg} / \mathrm{kg}$. The relative bioavailability of borneol:menthol eutectic solvents and microemulsions was increased by approximately 1.5 -fold and 3.65 times, correspondingly compared with a daidzein suspension. They concluded that a borneol/menthol eutectic mixture could increase the absorption of daidzein, but the mechanism of the increase in absorption was still uncleared. 


\subsection{DES Emulsion to nanosuspension.}

Phaechamud and Tuntarawongsa [65] transformed ibuprofen eutectic emulsion to nanosuspension with solvent evaporation and ultrasonication technique. They first formulated the emulsion with the help of an eutectic mixture [camphor:menthol (1:1)] and tween 20 as an emulsifying agent. The emulsion prepared with eutectic solvent was mixed in a homogenizer for $2 \mathrm{~min}$ and then with the help of probe ultrasonicator sonicated for $2 \mathrm{~min}$. Then, $25-\mathrm{mL}$ emulsion was diluted to $125 \mathrm{~mL}$ with a dilution medium (12.5 gm of glucose in water) to prevent water loss before conversion. For two days, they evaporated the diluted emulsion continuously under a laminar airflow hood with the help of a hot plate stirrer at $45^{\circ} \mathrm{C}$ and 200 rpm. Finally, the volume of the formulated suspension was adjusted to $25 \mathrm{~mL}$ with distilled water and further sonicated with a probe ultrasonicator. They successfully achieved the conversion mechanism.4.5. To stabilize the API.

Olivares et al. prepared a NADES consist of betaine and urea (1:1.5 molar) on a water bath at $60^{\circ} \mathrm{C}$. $\beta$-lactam antibiotics like Clavulanic acid and Imipenem monohydrate was incorporated into the above to make it stable. $\beta$-lactam antibiotics, once dissolved in aqueous solvents, have stability for about four to eight hours when stored at room temperature. Clavulanic acid and Imipenem monohydrate was completely dissolved in the betaine and urea (1:1.5 molar) NADES. The NADES were characterized with FT-IR, ${ }^{1} \mathrm{H}$ and ${ }^{13} \mathrm{C}$ NMR. Results showed that the obtained solvent has a microstructure mainly based on hydrogen bonding interactions, and water addition strongly affects its dynamic. Microbiological studies showed that antibacterial activity at day seven was significantly decreased for both Clavulanic acid and Imipenem monohydrate when dissolved in water, while no change in their antibacterial properties was observed when antibiotics were dissolved in betaine and urea [66].

\section{Funding}

This research received no external funding..

\section{Acknowledgments}

The access to scientific literature and lab facility to perform the stability studies are provided jointly by Vinayaka Mission's College of Pharmacy, Salem, and Sankaralingam Bhuvaneswari College of Pharmacy, Sivakasi.

\section{Conflicts of Interest}

The authors declare no conflict of interest.

\section{References}

1. Solvents. Available at https://www.chemicalsafetyfacts.org/solvents/ [accessed March 9, 2020].

2. Occupational safety and health solvents and the workplace. OSH Brief No. 5. Available at https://www.ilo.org/wcmsp5/groups/public/---americas/---ro-lima/---sroport_of_spain/documents/presentation/wcms_250196.pdf

3. Davis, S.J. Deep eutectic solvents derived from inorganic salts. University of Leicester. Thesis. 2015.

4. Pass, G.; Sutcliffe, H. Chemistry in non-aqueous solvents. In: Practical Inorganic Chemistry. Springer, Dordrecht, 1974; pp. 122-132, https://doi.org/10.1007/978-94-017-2744-0_13.

5. Morgan, C.M. Investigating eutectic mixtures for poorly soluble compounds. KU ScholarWorks. Thesis. 2014. 
6. Holliday, A.K.; Massey, A.G. Chapter I-The nature and scope of inorganic non-aqueous solvents. In: NonAqueous Solvents in Inorganic Chemistry. The Commonwealth and International Library: Chemistry Division, Pergamon Press, London, 1965; pp. 1-6, https://doi.org/10.1016/C2013-0-01906-8.

7. Lozowski, D. Supercritical $\mathrm{CO}_{2}$ : A green solvent. By Chemical Engineering. 2010.

8. Owczarek, K.; Szczepańska, N.; Płotka-Wasylka, J.; Rutkowska, M.; Shyshchak, O.; Bratychak, M.; Namieśnik, J. Natural Deep Eutectic Solvents in Extraction Process. Chemistry \& Chemical Technology 2016, 10, 601-606, https://doi.org/10.23939/chcht10.04si.601.

9. O’Neil, N.J.; Scott, S.; Relph, R.; Ponnusamy, E. Approaches to Incorporating Green Chemistry and Safety into Laboratory Culture. Journal of Chemical Education 2021, 98, 84-91, https://doi.org/10.1021/acs.jchemed.0c00134.

10. O’Neil, N.J.; Scott, S.; Relph, R.; Ponnusamy, E. Approaches to Incorporating Green Chemistry and Safety into Laboratory Culture. Journal of Chemical Education 2021, 98, 84-91, https://doi.org/10.3389/fchem.2020.00450.

11. Yilmaz, E.; Soylak, M. Chapter 5 - Type of green solvents used in separation and preconcentration methods. In: New Generation Green Solvents for Separation and Preconcentration of Organic and Inorganic Species. Editor(s): Soylak, M.; Yilmaz, E.; Elsevier: 2020; pp. 214, https://doi.org/10.1016/B978-0-12-8185698.00005-X.

12. Doble, M.; Kruthiventi, A.K. Chapter 5 - Alternate Solvents. In: Green Chemistry and Engineering. Editor(s): Doble M., Kruthiventi AK., Academic Press: 2007; pp 93-104, https://doi.org/10.1016/B978012372532-5/50006-7.

13. Phaechamud, T.; Tuntarawongsa, S.; Charoensuksai, P. Evaporation Behavior and Characterization of Eutectic Solvent and Ibuprofen Eutectic Solution. AAPS PharmSciTech 2016, 17, 1213-1220, https://doi.org/10.1208/s12249-015-0459-x.

14. Martins, M.A.R.; Pinho, S.P.; Coutinho, J.A.P. Insights into the Nature of Eutectic and Deep Eutectic Mixtures. Journal of Solution Chemistry 2019, 48, 962-982, https://doi.org/10.1007/s10953-018-0793-1.

15. Bernasconi, R.; Panzeri, G.; Accogli, A.; Liberale, F.; Nobili, L.; Magagnin, L. Chapter 11-Electrodeposition from Deep Eutectic Solvents. Progress and Developments in Ionic Liquids. Handy, S. IntechOpen, 2017; pp. 236, http://dx.doi.org/10.5772/64935.

16. Dai, Y.; van Spronsen, J.; Witkamp, G.-J.; Verpoorte, R.; Choi, Y.H. Ionic Liquids and Deep Eutectic Solvents in Natural Products Research: Mixtures of Solids as Extraction Solvents. Journal of Natural Products 2013, 76, 2162-2173, https://doi.org/10.1021/np400051w.

17. Smink, D.; Juan, A.; Schuur, B.; Kersten, S.R.A. Understanding the Role of Choline Chloride in Deep Eutectic Solvents Used for Biomass Delignification. Industrial \& Engineering Chemistry Research 2019, 58, 16348-16357, https://doi.org/10.1021/acs.iecr.9b03588.

18. Smith, E.L.; Abbott, A.P.; Ryder, K.S. Deep Eutectic Solvents (DESs) and Their Applications. Chemical Reviews 2014, 114, 11060-11082, https://doi.org/10.1021/cr300162p.

19. Mamashli, F.; Badraghi, J.; Delavari, B.; Sabbaghian, M.; Hosseini, M.; Saboury, A.A. Evaluation of Versatile Peroxidase's Activity and Conformation in the Presence of a Hydrated Urea Based Deep Eutectic Solvent. Journal of Solution Chemistry 2019, 48, 689-701, https://doi.org/10.1007/s10953-019-00881-3.

20. Aroso, I.M.; Silva, J.C.; Mano, F.; Ferreira, A.S.D.; Dionísio, M.; Sá-Nogueira, I.; Barreiros, S.; Reis, R.L.; Paiva, A.; Duarte, A.R.C. Dissolution enhancement of active pharmaceutical ingredients by therapeutic deep eutectic systems. European Journal of Pharmaceutics and Biopharmaceutics 2016, 98, 57-66, https://doi.org/10.1016/j.ejpb.2015.11.002.

21. Mirzaei, M.; Khorshahi, H.; Tebyanian, H.; Moradi, R.S.; Rastegar, M.; Panahi, S.; Sariri, R.; Latifi, A.M. The effect of deep eutectic solvents as co-solvent on organophosphorus hydrolase targeting engineering enzyme-catalyzed. Biointerface Research in Applied Chemistry 2020, 10, 6488-6497, https://doi.org/10.33263/BRIAC105.64886497.

22. Othman, Z.S.; Hassan, N.H.; Zubairi, S.I. Alcohol based-deep eutectic solvent (DES) as an alternative green additive to increase rotenone yield. AIP Conference Proceedings 2015, 1678, https://doi.org/10.1063/1.4931283.

23. Tuntarawongsa, S.; Phaechamud, T. Polymeric Eutectic System. Advanced Materials Research 2012, 528, 180-183, https://doi.org/10.4028/www.scientific.net/AMR.528.180.

24. Kalhor, P.; Ghandi, K. Deep Eutectic Solvents for Pretreatment, Extraction, and Catalysis of Biomass and Food Waste. Molecules 2019, 24, https://doi.org/10.3390/molecules24224012.

25. Shikov, A.N.; Kosman, V.M.; Flissyuk, E.V.; Smekhova, I.E.; Elameen, A.; Pozharitskaya, O.N. Natural Deep Eutectic Solvents for the Extraction of Phenyletanes and Phenylpropanoids of Rhodiola rosea L. Molecules 2020, 25, https://doi.org/10.3390/molecules25081826.

26. Santos, F.; P.S. Leitão, M.I.; C. Duarte, A.R. Properties of Therapeutic Deep Eutectic Solvents of l-Arginine and Ethambutol for Tuberculosis Treatment. Molecules 2019, https://doi.org/10.3390/molecules24010055.

27. Yue, Y.; Huang, Q.; Fu, Y.; Chang, J. A quick selection of natural deep eutectic solvents for the extraction of chlorogenic acid from herba artemisiae scopariae. RSC Advances 2020, 10, 23403-23409, https://doi.org/10.1039/D0RA03786A. 
28. Velásquez, P.; Bustos, D.; Montenegro, G.; Giordano, A. Ultrasound-Assisted Extraction of Anthocyanins Using Natural Deep Eutectic Solvents and Their Incorporation in Edible Films. Molecules 2021, $26,984$. https://doi.org/10.3390/molecules26040984.

29. Altunay, N.; Elik, A.; Gürkan, R. Natural deep eutectic solvent-based ultrasound-assisted-microextraction for extraction, pre-concentration and analysis of methylmercury and total mercury in fish and environmental waters by spectrophotometry. Food Additives \& Contaminants: Part A 2019, 36, 1079-1097, https://doi.org/10.1080/19440049.2019.1619939.

30. Islamčević Razboršek, M.; Ivanović, M.; Krajnc, P.; Kolar, M. Choline Chloride Based Natural Deep Eutectic Solvents as Extraction Media for Extracting Phenolic Compounds from Chokeberry (Aronia melanocarpa). Molecules 2020, 25, https://doi.org/10.3390/molecules25071619.

31. Mansur, A.R.; Song, N.-E.; Jang, H.W.; Lim, T.-G.; Yoo, M.; Nam, T.G. Optimizing the ultrasound-assisted deep eutectic solvent extraction of flavonoids in common buckwheat sprouts. Food Chemistry 2019, 293, 438-445, https://doi.org/10.1016/j.foodchem.2019.05.003.

32. [Ozturk, B.; Parkinson, C.; Gonzalez-Miquel, M. Extraction of polyphenolic antioxidants from orange peel waste using deep eutectic solvents. Separation and Purification Technology 2018, 206, 1-13, https://doi.org/10.1016/j.seppur.2018.05.052.

33. González, C.G.; Mustafa, N.R.; Wilson, E.G.; Verpoorte, R.; Choi, Y.H. Application of natural deep eutectic solvents for the "green"extraction of vanillin from vanilla pods. Flavour and Fragrance Journal 2018, 33, 91-96, https://doi.org/10.1002/ffj.3425.

34. Georgantzi, C.; Lioliou, A.E.; Paterakis, N.; Makris, D.P. Combination of Lactic Acid-Based Deep Eutectic Solvents (DES) with $\beta$-Cyclodextrin: Performance Screening Using Ultrasound-Assisted Extraction of Polyphenols from Selected Native Greek Medicinal Plants. Agronomy 2017, 7, https://doi.org/10.3390/agronomy7030054.

35. Bakirtzi, C.; Triantafyllidou, K.; Makris, D.P. Novel lactic acid-based natural deep eutectic solvents: Efficiency in the ultrasound-assisted extraction of antioxidant polyphenols from common native Greek medicinal plants. Journal of Applied Research on Medicinal and Aromatic Plants 2016, 3, 120-127, http://dx.doi.org/10.1016/j.jarmap.2016.03.003.

36. García, A.; Rodríguez-Juan, E.; Rodríguez-Gutiérrez, G.; Rios, J.J.; Fernández-Bolaños, J. Extraction of phenolic compounds from virgin olive oil by deep eutectic solvents (DESs). Food Chemistry 2016, 197, 554561, https://doi.org/10.1016/j.foodchem.2015.10.131.

37. Zhao, B.Y.; Xu, P.; Yang, F.X.; Wu, H.; Zong, M.H.; Lou, W.Y. Biocompatible Deep Eutectic Solvents Based on Choline Chloride: Characterization and Application to the Extraction of Rutin from Sophora japonica. ACS Sustainable Chemistry \& Engineering 2015; 3, 2746-2755. doi:10.1021/acssuschemeng.5b00619

38. Duarte, A.R.C.; Ferreira, A.S.D.; Barreiros, S.; Cabrita, E.; Reis, R.L.; Paiva, A. A comparison between pure active pharmaceutical ingredients and therapeutic deep eutectic solvents: Solubility and permeability studies. European Journal of Pharmaceutics and Biopharmaceutics 2017, 114, 296-304, https://doi.org/10.1016/j.ejpb.2017.02.003.

39. Tuntarawongsa, S.; Phaechamud, T. Menthol, Borneol, Camphor and WS-3 Eutectic Mixture. Advanced Materials Research 2012, 506, 355-358, https://doi.org/10.4028/www.scientific.net/AMR.506.355.

40. Gala, U.; Chuong, M.C.; Varanasi, R.; Chauhan, H. Characterization and Comparison of LidocaineTetracaine and Lidocaine-Camphor Eutectic Mixtures Based on Their Crystallization and HydrogenBonding Abilities. AAPS PharmSciTech 2015, 16, 528-536, https://doi.org/10.1208/s12249-014-0242-4.

41. Silva, J.M.; Pereira, C.V.; Mano, F.; Silva, E.; Castro, V.I.B.; Sá-Nogueira, I.; Reis, R.L.; Paiva, A.; Matias, A.A.; Duarte, A.R.C. Therapeutic Role of Deep Eutectic Solvents Based on Menthol and Saturated Fatty Acids on Wound Healing. ACS Applied Bio Materials 2019, 2, 4346-4355, https://doi.org/10.1021/acsabm.9b00598.

42. Silva, J.; Reis, R.; Paiva, A.; Duarte, A. Design of functional therapeutic deep eutectic solvents based on choline chloride and ascorbic acid. ACS Sustainable Chemistry \& Engineering 2018, 6, 10355-10363. https://doi:10.1021/acssuschemeng.8b01687

43. Ohzeki, K.; Kitahara, M.; Suzuki, N.; Taguchi, K.; Yamazaki, Y.; Akiyama, S.; Takahashi, K.; Kanzaki, Y. Local Anesthetic Cream Prepared from Lidocaine-Tetracaine Eutectic Mixture. Yakugaku Zasshi 2008, 128, 611-616, https://doi.org/10.1248/yakushi.128.611.

44. Yong, C.S.; Oh, Y.-K.; Jung, S.H.; Rhee, J.-D.; Kim, H.-D.; Kim, C.-K.; Choi, H.-G. Preparation of ibuprofen-loaded liquid suppository using eutectic mixture system with menthol. European Journal of Pharmaceutical Sciences 2004, 23, 347-353, https://doi.org/10.1016/j.ejps.2004.08.008.

45. Law, D.; Wang, W.; Schmitt, E.A.; Qiu, Y.; Krill, S.L.; Fort, J.J. Properties of Rapidly Dissolving Eutectic Mixtures of Poly(ethylene glycol) and Fenofibrate:The Eutectic Microstructure. Journal of Pharmaceutical Sciences 2003, 92, 505-515, https://doi.org/10.1002/jps.10324.

46. Nazzal, S.; Smalyukh, I.I.; Lavrentovich, O.D.; Khan, M.A. Preparation and in vitro characterization of a eutectic based semisolid self-nanoemulsified drug delivery system (SNEDDS) of ubiquinone: mechanism and progress of emulsion formation. International Journal of Pharmaceutics 2002, 235, 247-265, https://doi.org/10.1016/s0378-5173(02)00003-0. 
47. Stott, P.W.; Williams, A.C.; Barry, B.W. Transdermal delivery from eutectic systems: enhanced permeation of a model drug, ibuprofen. Journal of Controlled Release 1998, 50, 297-308, https://doi.org/10.1016/s0168-3659(97)00153-3.

48. Tuntarawongsa, S.; Phaechamud, T. Polymeric eutectic drug delivery system. Journal of Metals, Materials and Minerals 2012, 22.

49. Raja Sekharan, T.; Tamilvanan, S.; Rajadurai, S.; Mohammed, I.S.; Kavipriya, K. Development of Ibuprofen-loaded emulsion from eutectic mixture and Eudragit RL 100. PharmaTutor 2019, 7, 7-13; http://dx.doi.org/10.29161/PT.v7.i7.2019.7.

50. Ma, Y.; Wang, Q.; Zhu, T. Comparison of hydrophilic and hydrophobic deep eutectic solvents for pretreatment determination of sulfonamides from aqueous environments. Analytical Methods 2019, 11, 5901-5909. https://doi.org/10.1039/c9ay02244a.

51. van Osch, D.J.G.P.; Zubeir, L.F.; van den Bruinhorst, A.; Rocha, M.A.A.; Kroon, M.C. Hydrophobic deep eutectic solvents as water-immiscible extractants. Green Chemistry 2015, 17, 4518-4521, https://doi.org/10.1039/C5GC01451D.

52. van Osch, D.J.G.P.; Dietz, C.H.J.T.; van Spronsen, J.; Kroon, M.C.; Gallucci, F.; van Sint Annaland, M.; Tuinier, R. A Search for Natural Hydrophobic Deep Eutectic Solvents Based on Natural Components. ACS $\begin{array}{llllll}\text { Sustainable Chemistry } \quad \& \quad \text { Engineering } & \text { 2019, }\end{array}$ https://doi.org/10.1021/acssuschemeng.8b03520.

53. Dwamena, A.K. Recent Advances in Hydrophobic Deep Eutectic Solvents for Extraction. Separations 2019, 6, https://doi.org/10.3390/separations6010009.

54. Qu, Q.; Lv, Y.; Liu, L.; Row, K.H.; Zhu, T. Synthesis and characterization of deep eutectic solvents (five hydrophilic and three hydrophobic), and hydrophobic application for microextraction of environmental water samples. Analytical and Bioanalytical Chemistry 2019, 411, 7489-7498, https://doi.org/10.1007/s00216-019-02143-z.

55. Verma, R.; Banerjee, T. Palmitic-Acid-Based Hydrophobic Deep Eutectic Solvents for the Extraction of Lower Alcohols from Aqueous Media: Liquid-Liquid Equilibria Measurements, Validation and Process Economics. Global Challenges 2019, 3, https://doi.org/10.1002/gch2.201900024.

56. Lee, J.; Jung, D.; Park, K. Hydrophobic deep eutectic solvents for the extraction of organic and inorganic analytes from aqueous environments. TrAC Trends in Analytical Chemistry 2019, 118, 853-868, https://doi.org/10.1016/j.trac.2019.07.008.

57. Florindo, C.; Branco, L.C.; Marrucho, I.M. Development of hydrophobic deep eutectic solvents for extraction of pesticides from aqueous environments. Fluid Phase Equilibria 2017, 448, 135-142, https://doi.org/10.1016/j.fluid.2017.04.002.

58. Cao, J.; Chen, L.; Li, M.; Cao, F.; Zhao, L.; Su, E. Two-phase systems developed with hydrophilic and hydrophobic deep eutectic solvents for simultaneously extracting various bioactive compounds with different polarities. Green Chemistry 2018, 20, 1879-1886, https://doi.org/10.1039/C7GC03820H.

59. Yousefi, S.M.; Shemirani, F.; Ghorbanian, S.A. Hydrophobic Deep Eutectic Solvents in Developing Microextraction Methods Based on Solidification of Floating Drop: Application to the Trace HPLC/FLD Determination of PAHs. Chromatographia 2018, 81, 1201-1211, https://doi.org/10.1007/s10337-018-35487.

60. Ge, D.; Wang, Y.; Jianga, Q.; Daia, E. A deep eutectic solvent as an extraction solvent to separate and preconcentrate parabens in water samples using in situ liquid-liquid microextraction. J Braz Chem Soc 2019, 30, 1203-1210, https://doi.org/10.21577/0103-5053.20190014.

61. ZuŃ, M.; Wojciechowska, K.; Dwornicka, D.; Poleszak, E. The influence of the eutectic mixtures: Salicylic acid - menthol and benzocaine - menthol on physical properties of the creams with fluconazole. Current Issues in Pharmacy and Medical Sciences 2013, 26, 457-460, https://doi.org/10.12923/j.2084980X/26.4/a.24.

62. Tamilvanan, T.; Gill, S.; Kaur, I.; Rahman, S.N.R.; Pawde, D.M.; Katari, O.; Hmingthansanga, V.; Raja Sekharan, T. Candidiasis management: current status of allopathic drugs and utility of coriander-based oilless emulsions. Letters in Applied NanoBioScience 2019, 8, 586-590, https://doi.org/10.33263/LIANBS83.586590.

63. Biswal, B.; Karna, N.; Nayak, J.; Joshi, V. Formulation and evaluation of microemulsion based topical hydrogel containing lornoxicam. Journal of Applied Pharmaceutical Science 2014, 4, 077-084, https://doi.org/10.7324/JAPS.2014.41214.

64. Shen, Q.; Li, X.; Li, W.; Zhao, X. Enhanced Intestinal Absorption of Daidzein by Borneol/Menthol Eutectic Mixture and Microemulsion. AAPS PharmSciTech 2011, 12, 1044-1049, https://doi.org/10.1208/s12249011-9672-4.

65. Phaechamud, T.; Tuntarawongsa, S. Transformation of eutectic emulsion to nanosuspension fabricating with solvent evaporation and ultrasonication technique. Int $J$ Nanomedicine 2016, 11, 2855-2865, https://doi.org/10.2147/IJN.S108355.

66. Olivares, B.; Martínez, F.; Rivas, L.; Calderón, C.; M. Munita, J.; R. Campodonico, P. A Natural Deep Eutectic Solvent Formulated to Stabilize $\beta$-Lactam Antibiotics. Scientific Reports 2018, 8, https://doi.org/10.1038/s41598-018-33148-w. 